\title{
Parboiling Cereals in Sub-Saharan Africa: Case of Rice
}

\author{
Séye Sene ${ }^{1 *}$, Momar Talla Gueye ${ }^{1}$, Fallou Sarr ${ }^{1}$, Younoussa Diallo ${ }^{1}$, Ramatoulaye Fall ${ }^{1}$, Mohamed \\ Lamine Gaye ${ }^{2}$ \\ ${ }^{1}$ Institut de Technologie Alimentaire /Dakar/Senegal \\ ${ }^{2}$ Université Cheickh Anta DIOP/Dakar/Senegal
}

Received: December 28, 2016; Accepted: January 13, 2017; Published: February 20, 2017

*Corresponding author: Séye SENE, Institut de Technologie Alimentaire/Dakar/Senegal, Tél: (+221)77368 69 47/(+221)70672 16 21; E-mail: naboubocar@yahoo.fr

\begin{abstract}
In order to combat food insecurity and ensure food selfsufficiency, Senegal and most of the countries of sub-Saharan Africa have chosen to transform their local products into the agricultural food sector. Parboiling is one of the responses to this food insecurity. It is a post-harvest operation which results in physico-chemical and organoleptic modifications that are advantageous from the nutritional and economic point of view. This work, based on a through and up-todate documentary review, aims to make the genesis of the improved parboiling method of paddy rice by focusing on the technological and physico-chemical characteristics, the influence of certain factors on quality of rice parboiling, its impact and nutritional intakes.
\end{abstract} Intake

Keywords: Food Insecurity; Paddy Rice; Parboiling; Nutritional

\section{Introduction}

Until the beginning of the $3^{\text {rd }}$ millennium, malnutrition has continued to increase in developing countries despite the evolution of science in the field of agriculture. In its global campaign against hunger, the Food and Agriculture Organization of the United Nations (FAO), the International Fund for Agricultural Development (IFAD) and the World Food Program (WFP) estimate that 795 million people, or $1 / 9$ of the world's population, of whom 232.5 million Africans have suffered from chronic hunger undernourishment during the period 2014-2016 [1].

Agriculture with $7.86 \%$ of the gross domestic product [2] occupies a preponderant place in the economy of Senegal and sustains $60 \%$ of the population [3]. In fact, there are 755,532 farm households, more than $95 \%$ of which are active in this sector, which provides them with the main source of income. The majority of the crops grown are food, 91\% [4]. Countries of the south Sahara continue to varying degrees to carry out large-scale actions in peasant management in order to significantly increase production and market value of cereals (rice, millet, sorghum, etc.) and their by-products in order to achieve food self-sufficiency. Through sustained competition, rich countries impose their products and consumption patterns, thus weakening local production and, in turn, the economies concerned. To cope with this situation, major efforts are being made to increase production. In this context, the State of Senegal has always supported the promotion of local cereals through the implementation of specifically dedicated programs (GOANA, rice self-sufficiency, etc.). The development of the agro-food sector has received particular attention in recent years, making it one of the most dynamic sectors of the country's economy.

Cereals are the main staple foods in the Sahel countries and the world at large. Rice (Oryza sativa L.) is one of the most important food crops in the world [5] and is considered a major source of nutrients due to its daily intake $[6,7,8]$. This cereal is generally used in feeding after several post-harvest operations such as threshing, winnowing and milling [9]. The latter is a unitary processing operation which results in a loss of nutrients, in particular the mineral elements. Among the technologies developed to reduce nutrient losses during hulling, is parboiling. Rice parboiling consists a hydrothermal treatment of paddy rice followed by steaming and drying before milling [10, 11]. It is the most important operation with the potential to improve the efficiency of milling and the economic value of paddy rice as well as the nutritional quality of the finished product.

The aim of this bibliographic review is to present the current state of parboiling, with emphasis on technological and physicochemical characteristics, the influence of certain factors on quality of rice parboiling, its impact on rice quality and nutritional contributions.

\section{Methodology}

We have used the search engines:

The Google scholar database, a direct science on the key words "paddy rice and parboiling, parboiling and technological and physicochemical characteristics, parboiling and influence of certain factors on the quality and parboiling and its nutritional intakes" 
The duration of this bibliographic search was not limited and the documents consulted are written in French or English. To be more precise the documents consulted deal with the rice parboiling, the methodology used, the technological and physicochemical characteristics and the nutritional contribution.

A total of 31 articles, 1 thesis, 1 memory, 5 books and 11 reports were consulted.

\section{Results \\ Parboiling}

Parboiling is a hydrothermal treatment wherein a paddy is soaked in hot water, steamed to complete gelatinization, and dried before milled [11]. This technology adds value to quantitatively and qualitatively milled rice $[12,13,14,15]$.

Parboiling was traditionally practiced at the beginning of the 20th century in South-East Asia and tropical Africa and then from 1940 in the United States and Europe. It is a process of Indian origin, very ancient and very well known. It is applied in India, Bangladesh, Pakistan, Thailand, Brazil, France and the United States [16]. The traditional parboiling technique has been introduced in Benin by Malian women for several decades [17].

\section{Parboiling method used in sub-Saharan Africa}

Parboiling is well practiced in Africa, among others in Mali, Benin and Burkina Faso [18]. There are two methods of parboiling: the traditional method and the so-called improved method [13]. According to [19] the parboiling method used in Senegal and in the other countries of West Africa is the so-called improved method. Water and heat are the two main variables and allow the three stages of the parboiling process to be carried out $[20,19,21]$. These three phases are:

Soaking: It is the total immersion of the paddy in water to allow it to be completely hydrated. Beforehand, the paddy is cleaned dry and then with water and drained, which makes it possible to eliminate all the organic impurities and to sort it according to the thickness of the grains [22]. During this stage, water carries with it most of the nutrients of paddy rice from bran to grains [8].

Steaming: This is an important operation, which consists in steaming the paddy soaked, rewashed and drained until the gelatinization takes place. Optimal gelatinization can be observed when the hulls of most grains crack and open [23, 24].

Drying:This is the progressive reduction of the water content of the steamed paddy (greater than 30\%) to approximately 14 to $12 \%$ representing the minimum water content level required to ensure grain breakage during [25]. The steam-treated paddy is manually scattered in very thin layers on a spread sheet or on a well washed and dried concrete drying area. It is first dried in the sun for about 90 minutes to three hours then picked up and dried in the shade for the rest of the drying which can last about 16 hours before being husked. However, millers are advised to have instruments to measure grain moisture to ensure that this water content is actually reached. According to the dry women in the center of Songhaï, the end of drying in the shade is marked by the easy removal of the balls by friction of the paddy in the palms of both hands, which determines the end of the whole process of parboiling.

\section{The influence of certain factors on the quality of rice parboiling}

Type of paddy rice: In order to prevent fermentation, especially during the soaking process, it is essential to remove all organic impurities mixed with the paddy [26] indicates that it is necessary to have a good quality of paddy, that is to say which is not too old and does not have too many cracks because the quality of the final product also depends on that of the paddy used. If the grains are not all the same size, as often happens in the case of mixed varieties, the gelatinization of the albumen cannot be done uniformly. Indeed, thick grains require a longer time of soaking and steaming. If the processing time is increased, the thinner grains will become darker in color, become harder with a more compact shape. Once husking, the rice will have an irregular appearance, duration of cooking and variable organoleptic properties.

Soaking temperature: The soaking temperature is one of the most important stages in the process of parboiling. In most countries in sub-Saharan Africa, including Nigeria, hot water soaking is done by introducing paddy rice into hot water heated to $30-70^{\circ} \mathrm{C}$ and leaving it stand for $10-24$ hours after removal of the heat source $[14,27]$.

According to Cherati (2012)[28], there is a significant difference in the milling yields of the various tests and treatments performed. The highest percentage is obtained for soaking at 45 ${ }^{\circ} \mathrm{C}$. for 5 hours under atmospheric pressure [29] reported that soaking at $50{ }^{\circ} \mathrm{C}$ for 3 hours most provided the desired stewed rice quality from a nutritional and sensory point of view. Studies based on qualitative changes in parboiled rice have concluded that intermediate soaking temperatures $\left(60{ }^{\circ} \mathrm{C}\right.$ to $\left.70{ }^{\circ} \mathrm{C}\right)$ would be useful for soaking [30]. There is a correlation between the temperature of the soaking water and the soaking time Miah et al. (2002) [31] demonstrated that the higher the temperature of the soaking water, the lower the soaking time. However, the temperature of the soaking water should not exceed the gelatinization temperature of the paddy rice starch.

Soaking time: The soaking operation is the most critical of the three important steps of parboiling [32]. The water content sufficient to obtain adequate gelatinization in the steaming step depends on soaking [33]. Generally, the paddy is soaked in fresh water and heated to obtain a temperature of between 70 and $90{ }^{\circ} \mathrm{C}$. The fire is then switched off and the paddy is soaked for 12 to 16 hours [19]. If the soaked water can be stored at a constant temperature of $70^{\circ} \mathrm{C}$, the soaking period can be reduced to 5 hours [23] Bhattacharya et al. (1985) [34] reported that a moisture level of 40 to $45 \%$ is required during the soaking step to achieve the desired gelatinization of the starch. Soaking changes its raw composition and distribution of nutrients mainly in fiber, ash and minerals. The latter within the grains migrate with the soaking water, thus altering their distribution in the rice grains $[6,35]$. 
Kshirod et al. (2006)[36]reported that hot soaking and steaming conditions could also affect the color of parboiled rice [7] indicate that color is an important parameter of parboiled rice because it directly influences its nutritional value. If the soaking time is insufficient, all the paddy grains will not be well saturated with water, resulting in different colors of rice after milling. If the soaking is to excess, the parboiled rice will have a bad odor and it will be unpleasant to consume.

Steaming time: Steaming is a crucial step in the parboiling process which brings about the fundamental break in the properties of parboiled rice from those of raw rice. It allows a gelatinization of the starch which loses its crystalline structure. The duration of steaming, among other factors, plays an important role in the properties of parboiled rice. It depends on the arrangement of the vapor in the vessel and the amount of paddy affects the level of heat distribution and therefore the overall time for the process [37].

The level of moisture distribution in the rice grain during soaking, the duration and the intensity of the heat treatment have a great influence on the overall properties of the parboiled product [38]. Thus, [39] indicate that the presence of grains of white-heart rice is often associated with poor paddy rice steeping, either by poor paddy dipping or insufficient pre-cooking. In contrast, [35] reported that prolonged steaming leads to nutrient loss.

Nature and duration of drying: Drying, which entails the reduction in moisture content, completes the rice parboiling process. This is done to bring the moisture level of the parboiled product to about $12-13 \%$ representing the moisture content level required to ensure minimal grain breakage during milling [25]. As a best practice, drying should be done slowly so as to avoid internal stresses which could develop in the grain and cause breakage during milling [40,37].

\section{Impact and nutritional intake of rice parboiling}

Parboiling brings the specter of qualitative changes in rice. It affects the physical properties of rice, nutritional composition, starch characteristics (sticking properties and crystallinity), cooking qualities, etc. [41, 6, 11, 42, 43, 32]. According to these authors, the purpose of parboiling is to produce physico-chemical and organoleptic modifications that are advantageous from an economic, nutritional and practical point of view.

\section{Physical modifications}

They concern the drying which reduces the moisture content of the grain to the optimal level for milling. All the latent or active biological processes, namely germination, the proliferation of fungal spores, and the development of insects at different stages are definitively stopped. The milling yields efficiency is better and the quality is improved because there are fewer broken grains. Parboiled rice, whether milled or not, can be stored better and longer because the compact texture of the albumen allows it to withstand insect attack and mold growth [44]. Thus, [45] reported a significant reduction in cracked grain on parboiled rice. The parboiling process is applied to rice with a preliminary objective of hardening the kernel in order to maximize head rice yield in milling. However, hardness is one of the most important physical properties of parboiled rice because it reduces broken rice and nutrient losses during milling, which considerably increases the nutritional value and acceptability of consumers [7, 39].

\section{The chemical modifications}

The main chemical modifications are the dissolution and the diffusion of the water-soluble substances (vitamins and mineral salts) in all the grain, which modifies their distribution between the different parts of this one. Gelatinized starch is a compact, homogeneous mass. The lipids are separated and sink into the compact mass of gelatinized starch; they are therefore less subject to extraction. For this purpose, improvement of nutritional value such as B vitamins and other trace elements is the most important parameter among all the other properties of parboiled rice. Thus many researchers like [46] and [47] reported a marked increase in thiamine, riboflavin and nicotinic acid in parboiled rice. Like vitamins, sugars and amino acids, minerals also increase during rice steaming. Bhattacharya et al. (1985)[34] reported that changes in mineral elements are not as important. However, ash, phosphorus, calcium, iron, manganese, molybdenum and chromium were found to be higher in parboiled rice than in un-parboiled rice.

Thus, [35] reported a significant increase in hulling yield from $51 \%$ for brown rice to $80 \%$ for parboiled rice. The results also showed a significant increase in protein, lipid and ash content.

Besides milling yield, it was also the realization of the nutritional and health benefits of parboiled rice compared to raw rice that created the awareness and importance of parboiling among consumers and manufacturers [47]. Thus, the work carried out in [48] on a local variety showed that parboiled rice contains a good dietary value from the point of view of energy, protein, lipid, cellulosic and vitamin intakes. According to the author, parboiling rice retains its proteins and vitamins, keeps well and also retains good taste and market value. On the other hand, the non-parboiled rice under Guinean climate conditions loses almost all the B vitamins. It has a much lower protein content and is richer in carbohydrates than parboiled rice.

\section{The organoleptic modifications}

The most important is that the parboiled rice cooked is more digestible, because of its texture and firm consistency. In addition, after cooking, the grains are firmer and less prone to sticking. They thus conserve longer and rancid less [49].

\section{Conclusion}

The present study on parboiling in sub-Saharan Africa, carried out mainly through a review of the literature, made it possible its technological and physico-chemical characteristics, the influence of certain factors on the quality of parboiling, its impact and its nutritional intakes. Given the importance of this study and in order to encourage the emergence of post-harvest technologies that are efficient and adapted to local socio-economic conditions, 
it would be necessary to disseminate rice parboiling in Senegal and apply it to other cereals, namely millet, sorghum, and maize.

\section{Acknowledgement}

The Authors would like to thank the West Africa Agricultural Productivity Program (WAAPP) about its financial support.

\section{References}

1. FAO (Food and Agriculture Organization of the United Nations), IFAD (International Fund for Agricultural Development), WFP (World Food Program). The State of Food Insecurity in the World: 2015 International Targets for Reducing Hunger: Uneven Progress. Rome, FAO. 2015;pp.66.

2. Alsim FALL, Baidy Baro MBAYE, Hamat SY. DPEE (Department of Forecasting and Economic Studies). Agricultural Policy, Productivity and Long-Term Growth in Senegal. 2013;pp.16.

3. IMF (International Monetary Fund). Senegal: Annual Progress Report on the Poverty Reduction Strategy Paper. P-3, IMF Report No. 10/368. 2010;pp.58.

4. ANSD (National Agency for Statistics and Demography). General Census of Population and Housing, Agriculture and Livestock (RGPHAE 2013). 2014:pp.372.

5. Buggenhout J, Brijs K, Celus I, Delcour JA. The breakage susceptibility of raw and parboiled rice: A review. J of Food Eng. 2013;117(3):304315.

6. Heinemann RJB, Fagundes PL, Pinto EA, Penteado MVC, LanferMarquez UM. Comparative study of nutrient composition of commercial brown, parboiled and milled rice from Brazil. J of Food Comp Anal. 2005;18(4):287-296

7. Parnsakhorn S, Noomhorm A. Changes in physicochemical properties of parboiled brown rice during heat treatment. J of Agric Eng Int. 2008;10:8-9.

8. Khalil A, Shoaib M, Nadeem Akhtar M, Zafar Iqbal. Chemical analysis of different cereals to access nutritional components vital for human health. Int J of Chem and Biochem Sci. 2014 ;6:61-67

9. Takahashi T, Miura M, Ohisa N, Kobayashi S. Modification of gelatinization properties of rice flour by heat-treatment. Nihon Reoroji Gakkaishi. 2005;33(2):81-85.

10. Feillet P. Wheat grain: composition and use. INR. Paris. 2000;pp.303

11. Himmelsbach DS, Manful JT, Coker RD. Changes in rice with variable temperature parboiling: thermal and spectroscopic assessment. Cereal Chem. 2008 ;85 (3):384-390.

12. FAO (Food and Agriculture Organization of the United Nations). Development of a recovery plan for the rice sector in Benin. Final Report, Volumes 1 and 2, FAO / Project TCP / BEN / 5613 (A), Cotonou. 1997

13. Houssou P. Développement de l'étuvage du riz au Bénin. INRAB/PTAA. Acte de colloque, Garoua, Cameroun. 2003 ;pp.9.

14. Manful, JT, Grimm CC, Gayin J, Coker RD. Effect of variable parboiling on crystallinity of rice samples. J of Cereal Chem. 2008;85(1):92-95.

15. Fofana M, Wanvoeke J, Manful J, Futakuchi K, Van Mélé P, Zossou E, et al. Effect of improved parboiling methods on the physical and cooked grain characteristics of rice varieties in Benin. Int Food Res J. 2011;18:697-703.

16. Pillaiyar P. Rice parboiling. Research in India. Cereal Foods World. 1990;32(2):225-227.

17. Houndékon VA. Economic analysis of rice production systems in North Benin, Doctoral Thesis in Economic Sciences. (Rural economy), CIRES, Abidjan, Côte d'Ivoire. 1996;pp.237.

18. Himjyoti D, Mahanta CL. Traditional Parboiled Rice-Based Products Revisited: Current Status and Future Research Challenge. Rice Sci. 2014;21(4):187-200

19. CORAF/WECARD. 2009. Reference study of the program on agricultural productivity in Senegal under the WAAPP project.

20.GODON B, WILLM C. The primary processing industries for cereals. Tec and Doc. Lavoisier. Paris. 1998;pp.679.

21. Oluwa funmilayo A, OlusegunA, Mojisola E, Olusola O. Effect of Lactic Acid Bacteria and Yeast Starter Culture on the soaking time and quality of "Ofada". Rice Food and nutrition Sci. 2012;3(2):207-211

22. Cruz J-F, Dramé D. Post-harvest technologies of fonio. CFC project Improvement of fonio post-harvest technologies. [CD Rom], CIRAD, Montpellier, France. 2005.

23. CORAF/WECARD, 2011. Food Crops Program Global Food Security Response Initiative. Training Manual on Improving Post-Harvest Technologies for Rice. Cote D'Ivoire. 2011;47.

24. Longtau S. Multi-agency partnerships in West African Agriculture: A review and description of rice production systems in Nigeria. 2003;156

25. Biswas SK, Juliano BO. Laboratory parboiling procedures and properties of parboiled rice from varieties differing in starch properties. Cereal Chem. 1988;65(5):417-423.

26. Houssou P, Fandohan P, Mensah G. A, Klotoe A, et Megnanglo M. Fiche technique: Guide pratique pour l'utilisation du dispositif amélioré d'étuvage du riz. Bibliothèque Nationale (BN) du Bénin ISBN : 97899919-67-92-9, Bénin. 2008.

27. Ayamdoo AJ, Demuyakor B, Dogbe W, Owusu R, Ofosu MA. Effect of varying parboiling conditions on physical qualities of Jasmine 85 and Nerica 14 varieties. Amer. J of Food Tech. 2013;8(1):31-42.

28. Fnazlollah Eskandari C, Soheila K, Shekofteh M, Razie Derikvand R. Analysis and Study of Parboiling Method and the Following Impact on Waste Reduction and Operation Increase of Rice in Paddy Conversion Phase. Research Journal of Applied Sciences, Engineering and Technology. 2012;4(16):2649-2652

29. Sareepuang K, Siri Amornpun S, Wiset L, N Meeso N. Effect of Soaking Temperature on Physical, Chemical and Cooking Properties of Parboiled Fragrant Rice. World Journal of Agricultural Sciences. 
2008;4(4):409-415.

30. Kale SJ, Jha SK, Jha GK, SINHA JP, LAL SB. Soaking Induced Changes in Chemical Composition, Glycemic Index and Starch Characteristics of Basmati Rice. Rice Science. 2015;22(5):227-236.

31. Kaddus Miah MA, Haque A, Douglas MP, Clarke B. Parboiling of rice: Part II. Effect of hot soaking time on the degree of starch gelatinization. Int J Food Sci Technol. 2002;37(5):539-545.

32. Mir SA, Bosco SJD. Effect of soaking temperature on physical and functional properties of parboiled rice cultivars grown in temperate region of India. Food Nutr. Sci. 2013;4(3):282-288. DOI: 10.4236/ fns. 2013.43038

33. Bello M, Baeza R, Tolaba MP. Quality characteristics of milled andcooked rice affected by hydrothermal treatment. J of Food Eng. 2006;72(2):124-133.

34. Bhattacharya KR. Parboiling of rice. In: Juliano BO. Rice Science and Technology. St. Paul, Minnesota, USA: AACC International. 1985;289348.

35. Ibukun EO. Effect of prolonged parboiling duration on proximate composition of rice. Sci Res Essay. 2008;3(7):323-325.

36. Kshirod R, Bhattacharya PV, SubbaRao. Effect of processing conditions on quality of parboiled rice. 2006.

37. Wimberly JE. Parboiling. In: Technical Hand Book for the Paddy Rice Post Harvest Industry in Developing Countries. 1983;101-116.

38. Velupillai L, Verma LR. Parboiled rice quality as affected by the level and distribution of moisture after the soaking process. Trans. ASAE. $1982 ; 25(5): 1450-1456$.

39. Bleoussi TM, Rosaline, Fofana M, Bokossa I, Koichi F. Effet of parboiling and storage on grain physical and cooking characteristic of the some NERICAN rice variety. Second Africa Rice congress, Bamako, Mali. 2010;22-26.
40. Lançon F, Erenstein O, Akande SO, Titilola SO, Akpokodje G, Ogundele 00. Rice processing in Nigeria: A survey. Project report - The Nigerian rice economy in a competitive world: constraints, opportunities and strategic choices. s. Abidjan:WARDA. 2003;pp.41.

41. Otegbayo BO, Osamuel F, Fashakin JB. 2001. Effect of parboiling on physico-chemical qualities of two local rice varieties in Nigeria. J Food Techno. 2001;6(4):130-132.

42. Patindol J, Newton J, Wang YJ. Functional properties as affected by laboratory-scale parboiling of rough rice and brown rice. J Food Sci. 2008;73(8):370-377. doi: 10.1111/j.1750-3841.2008.00926.x.

43. Dutta H, Mahanta CL. Effect of hydrothermal treatment varying in time and pressure on the properties of the parboiled rice with different amylose content. Food Res Int. 2012;49:655-663.

44. Elbert GM, Tolaba P, C Suárez. Effects of drying conditions on head rice yield and browning index of parboiled rice. J Food Eng. 2000;47(1):3741.

45. Miah MAK, Haque A, Douglass MP, Clarke B. Parboiling of rice. Part I: Effect of hot soaking time on the quality of milled rice. Int J of Food Sci and Tech. 2002;37(5):527-537.

46. Bhattacharya KR, Subba Rao PV. Processing conditions and milling yield in parboiling of rice. J Agric Food Chem. 1996;14(5):473-475.

47. Manful JT, Swetman AA, Coker RD Drunis A. Changes in the thiamine and riboflavin contents of rice during artisanal parboiling in Ghana, Trop Science. 2007;47(4):211-217.

48. Larsen HN, OW Rasmussen, PH Rasmussen, KK Alstrup, SK Biswas, I Tetens, et al. Glycaemic Index of Parboiled Rice Depends on the Severity of Processing: Study in Type 2 Diabetic Subjects. Europ J Clin Nutr. 2000;54(5):380-385.

49. Condé N. Comparative study of the nutritional value of parboiled and unfermented rice: case of a local variety. Graduate dissertation, University of Conakry, Guinea. 2000;pp.25. 